\title{
Quality of life and mental health status among the caregivers of genetic disease patients in Southern Karnataka, India
}

\author{
Aparna Mohandas $^{\mathrm{a}, *}$, Deepa Bhat ${ }^{\mathrm{b}}$, Sunil Kumar D ${ }^{\mathrm{c}}$, M.R. Narayana Murthy ${ }^{\mathrm{d}}$

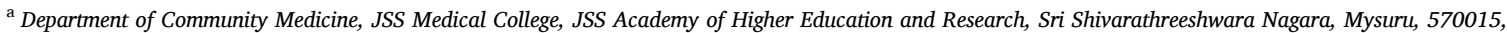 \\ Karnataka, India \\ ${ }^{\mathrm{b}}$ Department of Anatomy, JSS Medical College, JSS Academy of Higher Education and Research, Sri Shivarathreeshwara Nagara, Mysuru, 570015, Karnataka, India \\ ${ }^{\mathrm{c}}$ Department of Community Medicine, JSS Medical College, JSS Academy of Higher Education and Research, Sri Shivarathreeshwara Nagara Mysuru, 570015, \\ Karnataka, India \\ ${ }^{\mathrm{d}}$ Department of Community Medicine, JSS Medical College, JSS Academy of Higher Education and Research, Sri Shivarathreeshwara Nagara, Mysuru, 570015, \\ Karnataka, India
}

\section{A R T I C L E I N F O}

\section{Keywords:}

Quality of life

Depression

Anxiety

Genetic diseases

Caregivers

Stress

\begin{abstract}
A B S T R A C T
Objectives: The burden due to genetic diseases and congenital anomalies are on a rise. These diseases have an impact on several implications of life, ranging from economic burden, lifelong dependency and associated social stigma. The present study was conducted to assess the quality of life and mental health status among caregivers of genetic disease patients in Southern Karnataka, India.

Methods: This cross sectional study was conducted among 101 caregivers of genetic disease patients attending a tertiary care hospital in Southern Karnataka, India for a period of one and half years. After obtaining consent, sociodemographic data was collected. WHO-BREF and DASS-21 tools were used to assess the quality of life and mental health status, respectively. SPSS V.22 was used for statistical analysis. Quantitative data showing nonparametric distribution was expressed as median, interquartile range. Inferential statistical tests like Mann Whitney $U$ test and Kruskal Wallis test were used.

Results: The median quality of life score was 81 with interquartile range of 75-81 in Domain 1(Physical health), 69 with interquartile range of 56-75 in Domain 2(Psychological domain), 75 with interquartile range of 56-75 in Domain 3(Social relationships) and 69 with interquartile range of 63-75 in Domain 4 (Environment). The median score of depression among the participants was 2 with an interquartile range of $0-7$, anxiety was 0 and that of stress was 2 with an interquartile range of 0-8. Females had higher depression, anxiety and stress scores. Conclusion: Psychological health, environment and social relationships were affected the most. Awareness, service accessibility along with psychosocial support can help in positive adaptation.
\end{abstract}

\section{Introduction}

Over the years the burden due to genetic diseases and congenital anomalies are on a rise. Moreover advancements in various dimensions of life has added to the survival, thus increasing the morbidity and impairment associated with these diseases. While anomalies like cleft lip and palate, clubfoot can be corrected with surgical and medical methods, major anomalies associated with heart, neural tube defects, Down syndrome have lifelong impacts including economic cost and permanent disability. ${ }^{1}$ About 7.9 million children are born every year with serious birth defects of genetic etiology which contributes to 3.3 million deaths worldwide, most being reported from the economically backward countries. ${ }^{2}$ India is known to be home for all known genetic diseases with 1 in every 20 children being diagnosed to have a genetic disease. $^{3}$

The impact of genetic diseases has several implications on life, ranging from the emotional turmoil, economic burden, lifelong dependency and the associated social stigma. ${ }^{1}$ The World health organization(WHO) defines quality of life(QoL) as "an individual's perception of their position in life in the context of the culture and value systems in which they live, and in relation to their goals, expectations, standard and concerns". ${ }^{4}$ Quality of life and mental health of the caretakers can be

\footnotetext{
* Corresponding author.

E-mail addresses: aparnacnair90@gmail.com (A. Mohandas), deepabhat@jssuni.edu.in (D. Bhat), sunilkumard@jssuni.edu.in (S. Kumar D), drmrnmurthy@yahoo. co.in (M.R. Narayana Murthy).
} 
significantly influenced by factors like accepting the child's diagnosis, the associated functional issues, lack of access to sufficient information and changes in their daily life-including their physical, mental and social dimensions. Down syndrome babies for example show a slower development compared to other children which can result in care givers having to dedicate significantly to the care for these children. ${ }^{5}$ Diseases like muscular dystrophies are crippling, wherein the patients require lifelong ambulatory support, often increasing anxiety and depression among the caregivers and significantly affecting their health related quality of life. $^{6}$

The uncertainty about the occurrence and course of the disease with the cost of investigations and treatment also adds to the anxiety and stress among the caregivers. ${ }^{7}$ Hence emphasizing the fact that these diseases have an economic as well as functional impact, making it a public health problem, especially in the low resource settings. With this background the present study was conducted to assess the quality of life and mental health status among caregivers of genetic disease patients in Southern Karnataka, India.

\section{Materials and method}

\subsection{Study design and population}

This cross sectional study was conducted among 101 caregivers of genetic disease patients attending a tertiary care hospital in Southern Karnataka, India, for a period of one and half years, from January 2019 to July 2020. Consecutive sampling was used to select the participants visiting the genetic clinic. Participants of all age group who consented were included in the study.

\subsection{Ethical statement}

The study was commenced after obtaining the institutional ethics committee clearance. Before beginning the interview, study details were explained to the participants and informed consent was taken.

\subsection{Data collection}

Patients were recruited as and when they visited the genetic clinic. This included patients coming to Outpatient department as well as inpatients referred from department of Pediatrics and Obstetrics. Details regarding socio-demographic characteristics like age, place of residence, religion, education and occupation were collected using a semistructured questionnaire using interview method.

Final diagnosis of the patient was obtained and categorized as structural or functional genetic diseases.

\subsubsection{Structural diseases-}

Refers to defects in body structure including skeletal system and organs. It includes external as well as internal defects. Includes neural tube defects, cleft lip, cleft palate, congenital heart diseases, Down syndrome, Edward syndrome, cystic kidney disease, skeletal and limb deformities and indeterminate sex.

\subsubsection{Functional diseases-}

Functional defects in the neurological, muscular, immunological or endocrine system. Includes metabolic disorders, cystic fibrosis, muscular dystrophy, behavioral disorders and neurological disorders. ${ }^{8}$

WHO-BREF tool was used to assess the quality of life scores in 4 domains. The instrument has 26 items: 2 items pertaining to the overall perception of quality of life and health, 24 questions cover the four domains such as physical health (Domain 1), psychological health (Domain 2), social relationships (Domain 3) and environmental (Domain 4). Instructions given at the starting of the questionnaire was read out before reading out the questions. Each item is scored in a Likert scale of 1-5. Individual domain scores were calculated as per instructions and transformed into scores of 0-100. Higher the scores, better the quality of life.

DASS-21 tool was used to assess the mental health status of the caregivers. DASS-21 is a pre validated questionnaire consisting of three sets of seven questions to assess the level of depression, anxiety and stress. Each item is on a Likert scale from 0 to 3 . Each subset scores were calculated at the end as per the guidelines. Higher the scores, more the depression, anxiety and stress.

\subsection{Statistical analysis}

Data was entered in Microsoft Excel 2013 spreadsheet and analyzed using SPSS V.22 (Licensed to JSS AHER). Qualitative variables like gender, religion, place of residence etc. were represented using proportions. Quantitative data such as scores showing non-parametric distribution was expressed as median and interquartile range. Mann Whitney $U$ test and Kruskal Wallis test were used to compare median scores across different groups, as appropriate. Correlation between quality of life domains and depression, anxiety and stress was inferred using Pearson correlation. A p value less than 0.05 was considered statistically significant.

\section{Results}

Among the 101 caregivers interviewed, 66 (65.3\%) were females and $35(34.7 \%)$ were males. $35.6 \%$ were between 18 and 27 years, $46.5 \%$ between 28 and 37 years and $17.8 \%$ were above 38 years.52.5\% were from rural and $47.5 \%$ from urban areas. $83.2 \%$ belonged to the Hindu religion, $15.8 \%$ followed Islam and $1 \%$ followed Christianity. $8.9 \%$ belonged to upper, $16.8 \%$ to upper middle, $10.9 \%$ to middle, $28.7 \%$ to lower middle and $34.7 \%$ to lower socioeconomic class, according to modified B.G Prasad classification. $49.5 \%$ belonged to nuclear families, $18.8 \%$ to joint families and $31.7 \%$ to three generation families. Among the 101 caregivers, $4 \%$ were illiterates, $19.8 \%$ were educated up to primary school, $6.9 \%$ till middle school, $35.6 \%$ till high school, $22.8 \%$ had completed pre university course and $10.9 \%$ were graduates/post graduates. Among the caregivers $1 \%$ were professionals, $4 \%$ were semiprofessionals, $11.9 \%$ were clerks/shop-owners/farmers, $5.9 \%$ were skilled workers, $10.9 \%$ were semi-skilled workers, $20.8 \%$ were unskilled workers and $45.5 \%$ were unemployed. $35.6 \%$ of them cared for children with structural genetic diseases and $64.4 \%$ for functional genetic diseases.

On assessing the quality of life scores across various domains, the median quality of life score was 81 with an interquartile range of 75-81 in Domain 1(Physical health), 69 with an interquartile range of 56-75 in Domain 2(Psychological domain), 75 with an interquartile range of 56-75 in Domain 3(Social relationships) and 69 with an interquartile range of 63-75 in Domain 4 (Environment). The median scores across various socio-demographic variables are represented in Table 1 . There was a significant difference in median scores in quality of life in Domain 3(Social relationships) with respect to the type of genetic diseases being cared for and in Domain 4(Environment) with respect to religion and socio-economic class.

Among the 101 caregivers, on categorizing based on depression scores, $77.22 \%$ were normal. $17.82 \%$ had mild to moderate depression and $4.95 \%$ had severe depression. On categorizing anxiety scores, $89.10 \%$ were normal, $8.91 \%$ had mild to moderate anxiety and $1.98 \%$ had severe anxiety. $89.10 \%$ were normal while $10.89 \%$ had mild to moderate stress. The median scores are presented in Table 2.

The median score of depression among the participants was 2 with an interquartile range of $0-7$. Median score of anxiety was 0 and that of stress was 2 with an interquartile range of $0-8$. The median scores across various sociodemographic factors are represented in Table 3. There was a significant difference in median scores of depression, anxiety and stress across males and females. Scores were higher in females. Median scores of anxiety was also significantly different across age groups. Score 
Table 1

Median scores of the quality of life in Domains across various sociodemographic factors; $\mathrm{N}=101$.

\begin{tabular}{|c|c|c|c|c|c|c|c|c|c|}
\hline Variable & & $\begin{array}{l}\text { Domain } 1 \text { QOL } \\
\text { Scores (1-100) } \\
\text { Median } \\
\text { (IQR) }\end{array}$ & $\begin{array}{l}\mathrm{P} \\
\text { value }\end{array}$ & $\begin{array}{l}\text { Domain } 2 \text { QOL } \\
\text { Scores (1-100) } \\
\text { Median } \\
\text { (IQR) }\end{array}$ & $\begin{array}{l}\mathrm{P} \\
\text { value }\end{array}$ & $\begin{array}{l}\text { Domain } 3 \text { QOL } \\
\text { Scores (1-100) } \\
\text { Median } \\
\text { (IQR) }\end{array}$ & $\begin{array}{l}\mathrm{P} \\
\text { value }\end{array}$ & $\begin{array}{l}\text { Domain } 4 \text { QOL } \\
\text { Scores (1-100) } \\
\text { Median } \\
\text { (IQR) }\end{array}$ & $\begin{array}{l}\mathrm{P} \\
\text { value }\end{array}$ \\
\hline Gender & $\begin{array}{l}\text { Male } \\
\text { Female }\end{array}$ & $\begin{array}{l}81(75-81) \\
81(75-81)\end{array}$ & $.55^{\mathrm{b}}$ & $\begin{array}{l}69(63-75) \\
69(56-75)\end{array}$ & $.816^{\mathrm{b}}$ & $\begin{array}{l}75(69-75) \\
75(54.5-75)\end{array}$ & $.348^{\mathrm{b}}$ & $\begin{array}{l}69(63-75) \\
69(56-75)\end{array}$ & $.671^{b}$ \\
\hline Age categories & $\begin{array}{l}18-27 \text { years } \\
28-37 \text { years } \\
>/=38 \text { years }\end{array}$ & $\begin{array}{l}81(76.5-81) \\
81(75-81) \\
81(79.5-81)\end{array}$ & $.588^{c}$ & $\begin{array}{l}69(56-69) \\
69(56-75) \\
69(56-75)\end{array}$ & $.762^{c}$ & $\begin{array}{l}75(51-75) \\
75(69-75) \\
75(59.25-75)\end{array}$ & $.897^{\mathrm{c}}$ & $\begin{array}{l}69(56-69) \\
69(69-75) \\
72(63-75)\end{array}$ & $.115^{c}$ \\
\hline Place of residence & $\begin{array}{l}\text { Urban } \\
\text { Rural }\end{array}$ & $\begin{array}{l}81(76.5-81) \\
81(75-81)\end{array}$ & $.868^{\mathrm{b}}$ & $\begin{array}{l}69(57.75-75) \\
69(56-69)\end{array}$ & $.649^{\mathrm{b}}$ & $\begin{array}{l}75(59.25-75) \\
75(56-75)\end{array}$ & $.538^{\mathrm{b}}$ & $\begin{array}{l}69(63-75) \\
69(56-75)\end{array}$ & $.196^{\mathrm{b}}$ \\
\hline Religion & $\begin{array}{l}\text { Hindu } \\
\text { Muslim } \\
\text { Christian }\end{array}$ & $\begin{array}{l}81(75-81) \\
81(72-81) \\
81\end{array}$ & $.836^{c}$ & $\begin{array}{l}69(56-69) \\
72(57.75-75)\end{array}$ & $.343^{c}$ & $\begin{array}{l}75(56-75) \\
75(54.75-75) \\
75\end{array}$ & $.675^{c}$ & $\begin{array}{l}69(56-69) \\
75(70.5-75) \\
69\end{array}$ & $.001^{\mathrm{c}}$ \\
\hline Type of family & $\begin{array}{l}\text { Nuclear family } \\
\text { Joint family } \\
\text { Three } \\
\text { Generation family }\end{array}$ & $\begin{array}{l}81 \\
81(69-81) \\
81(75-81)\end{array}$ & $.156^{c}$ & $\begin{array}{l}69(56-75) \\
69(56-75) \\
69\end{array}$ & $.412^{\mathrm{c}}$ & $\begin{array}{l}75(56-75) \\
75(69-75) \\
75(56-75)\end{array}$ & $.913^{c}$ & $\begin{array}{l}69(63-75) \\
69(56-75) \\
69(57.75-75)\end{array}$ & $.957^{c}$ \\
\hline Level of education & $\begin{array}{l}\text { Illiterate } \\
\text { Primary } \\
\text { School } \\
\text { Middle } \\
\text { School } \\
\text { High school } \\
\text { PUC/Diploma } \\
\text { Graduate/Post } \\
\text { graduate }\end{array}$ & $\begin{array}{l}81 \\
81 \\
81(75-81) \\
81(75-81) \\
81(75-81) \\
81(69-81)\end{array}$ & $.710^{c}$ & $\begin{array}{l}63(53.25-76) \\
69(56-75) \\
69(56-75) \\
69(56-75) \\
69(63-75) \\
69(50-75)\end{array}$ & $.727^{c}$ & $\begin{array}{l}75(60.75-75) \\
75 \\
75 \\
75(45.5-75) \\
75(69-75) \\
75(50-75)\end{array}$ & $.377^{c}$ & $\begin{array}{l}72(59.25-75) \\
69(63-75) \\
69(63-75) \\
69(63-69) \\
69(56-75) \\
75(56-75)\end{array}$ & $.563^{c}$ \\
\hline Occupation & $\begin{array}{l}\text { Unemployed } \\
\text { Unskilled worker } \\
\text { Semi-skilled worker } \\
\text { Skilled worker } \\
\text { Clerk/shop-owner/ } \\
\text { farmer } \\
\text { Semi-professional } \\
\text { Professional }\end{array}$ & $\begin{array}{l}81 \\
81(75-81) \\
81(63-81) \\
75(67.5-81) \\
81(76.5-81) \\
81(72-81) \\
81\end{array}$ & $.200^{c}$ & $\begin{array}{l}69(56-75) \\
69(56-69) \\
69(56-81) \\
63(56-69) \\
75(69-75) \\
69(54.75-73.5) \\
69\end{array}$ & $.183^{c}$ & $\begin{array}{l}75(50-75) \\
75(50-75) \\
75 \\
59.5(45.25-70.5) \\
75(70.5-75) \\
75(60.75-75) \\
75\end{array}$ & $.101^{\mathrm{c}}$ & $\begin{array}{l}69(61.25-75) \\
69(59.5-75) \\
75(63-75) \\
62.5(48.5-69) \\
72(63-75) \\
69(45.75-69) \\
81\end{array}$ & $.200^{c}$ \\
\hline Socio-Economic class & $\begin{array}{l}\text { Upper class } \\
\text { Upper middle class } \\
\text { Middle class } \\
\text { Lower middle class } \\
\text { Lower class }\end{array}$ & $\begin{array}{l}81(78-81) \\
81 \\
81 \\
81(75-81) \\
81(75-81)\end{array}$ & $.734^{c}$ & $\begin{array}{l}69(50-75) \\
69(63-75) \\
69(56-75) \\
69(59.5-69) \\
69(56-75)\end{array}$ & $.812^{c}$ & $\begin{array}{l}75 \\
75(50-75) \\
69(44-75) \\
75(69-75) \\
75(44-75)\end{array}$ & $.205^{c}$ & $\begin{array}{l}69(69-75) \\
69(62.5-75) \\
63(50-63) \\
69(66-75) \\
69(63-75)\end{array}$ & $.035^{\mathrm{c}}$ \\
\hline $\begin{array}{l}\text { Type of genetic disease } \\
\text { being cared for }\end{array}$ & $\begin{array}{l}\text { Structural genetic } \\
\text { disease } \\
\text { Functional genetic } \\
\text { disease }\end{array}$ & $\begin{array}{l}81(75-81) \\
81(78-81)\end{array}$ & $.436^{\mathrm{b}}$ & $\begin{array}{l}69(56-69) \\
69(63-75)\end{array}$ & $.067^{\mathrm{b}}$ & $\begin{array}{l}75 \\
75(50-75)\end{array}$ & $.048^{b}$ & $\begin{array}{l}69(56-75) \\
69(63-75)\end{array}$ & $.385^{\mathrm{b}}$ \\
\hline
\end{tabular}

IQR- Inter quartile range.

${ }^{\mathrm{a}} \mathrm{p}$ value $<0.05$ is statistically significant.

b -Mann Whitney $U$ test.

c -Kruskal Wallis test.

Table 2

Median scores for depression, anxiety and stress among the caregivers; $\mathrm{N}=101$.

\begin{tabular}{lll}
\hline & Median score & Interquartile range(IQR) \\
\hline Depression & 2 & $(0-7)$ \\
Anxiety & 0 & $(0-2)$ \\
Stress & 2 & $(0-8)$ \\
\hline
\end{tabular}

was higher in the lower age group of care givers.

On assessing the correlation between quality of life and depression, anxiety and stress, there was a negative correlation between all domains of quality of life and depression, anxiety and stress scores implying that lower quality of life scores were associated with more depression, anxiety and stress. Among these, significant correlation was seen between depression and all QoL domains, anxiety with psychological and environmental domain and stress with psychological, social and environmental domain (Table 4).

\section{Discussion}

In the present study, Psychological domain showed a median score of 69 with an interquartile range of 56-75 and environmental domain had a median score of 69 with an interquartile range of $63-75$, implying that psychological domain was affected the most. Similar findings were reported by Buzatto et al. among parents of Down syndrome children, where the psychological domain was the most affected followed by environmental domain. Caregivers often face multitude of challenges, initially with accepting the diagnosis of their child, uncertainty about the disease, handling their own anxiety and that of the family, meeting the demands of the child and adjusting their life in all dimensions so as 
Table 3

Median scores of Depression, anxiety and stress across various sociodemographic factors; $\mathrm{N}=101$.

\begin{tabular}{|c|c|c|c|c|c|c|c|}
\hline Variable & & $\begin{array}{l}\text { Median Depression scores } \\
\text { with IQR }\end{array}$ & $\begin{array}{l}\mathrm{P} \\
\text { value }\end{array}$ & $\begin{array}{l}\text { Median anxiety scores } \\
\text { with IQR }\end{array}$ & $P$ value & $\begin{array}{l}\text { Median stress scores } \\
\text { with IQR }\end{array}$ & $P$ value \\
\hline Gender & $\begin{array}{l}\text { Male } \\
\text { Female }\end{array}$ & $\begin{array}{l}2(0-2) \\
4(0-10)\end{array}$ & $.004^{\mathrm{a}}$ & $\begin{array}{l}0 \\
2(0-2)\end{array}$ & $<_{b} .001^{a}$ & $\begin{array}{l}2(0-4) \\
5(0-12)\end{array}$ & $<.001^{\mathrm{a}}$ \\
\hline Age categories & $\begin{array}{l}18-27 \text { years } \\
28-37 \text { years } \\
>/=38 \text { years } \\
\end{array}$ & $\begin{array}{l}4(0-10) \\
2(0-6) \\
1(0-3)\end{array}$ & $.109^{\mathrm{c}}$ & $\begin{array}{l}2(0-6) \\
0(0-2) \\
0(0-2) \\
\end{array}$ & $.005^{\mathrm{a} \mathrm{c}}$ & $\begin{array}{l}7(0-12) \\
2(0-6) \\
1(0-4)\end{array}$ & $.101^{\mathrm{c}}$ \\
\hline Place of residence & $\begin{array}{l}\text { Urban } \\
\text { Rural }\end{array}$ & $\begin{array}{l}2(0-7.5) \\
2(0-7)\end{array}$ & $.760^{\mathrm{b}}$ & $\begin{array}{l}0(0-2) \\
0(0-2)\end{array}$ & $.841^{\mathrm{b}}$ & $\begin{array}{l}2(0-8) \\
4(0-8)\end{array}$ & $.752^{\mathrm{b}}$ \\
\hline Religion & $\begin{array}{l}\text { Hindu } \\
\text { Muslim } \\
\text { Christian }\end{array}$ & $\begin{array}{l}2(0-8) \\
3(2-6) \\
0 \\
\end{array}$ & $.356^{c}$ & $\begin{array}{l}0(0-2) \\
1(1-3.5) \\
0\end{array}$ & $.627^{\mathrm{c}}$ & $\begin{array}{l}2(0-8) \\
4(2-8) \\
0\end{array}$ & $.263^{c}$ \\
\hline Type of family & $\begin{array}{l}\text { Nuclear family } \\
\text { Joint family } \\
\text { Three generation } \\
\text { family }\end{array}$ & $\begin{array}{l}2(0-6.5) \\
4(2-6) \\
2(0-10)\end{array}$ & $.504^{c}$ & $\begin{array}{l}0(0-2) \\
0(0-2) \\
0(0-3.5)\end{array}$ & $.645^{c}$ & $\begin{array}{l}2(0-8.5) \\
4(2-8) \\
2(0-8)\end{array}$ & $.499^{c}$ \\
\hline Level of education & $\begin{array}{l}\text { Illiterate } \\
\text { Primary school } \\
\text { Middle school } \\
\text { High school } \\
\text { PUC/Diploma } \\
\text { Graduate/Post } \\
\text { Graduate }\end{array}$ & $\begin{array}{l}3(.5-5.5) \\
2(0-6) \\
2(0-6) \\
2(0-9.5) \\
2(0-6) \\
8(2-12)\end{array}$ & $.383^{c}$ & $\begin{array}{l}0 \\
0(0-2 \\
0(0-2) \\
1(0-5.5) \\
0(0-2) \\
2(0-4)\end{array}$ & $.153^{\mathrm{c}}$ & $\begin{array}{l}1(0-3.5) \\
2(0-4) \\
0 \\
3(0-10) \\
4(0-10) \\
8(2-16)\end{array}$ & $.253^{\mathrm{c}}$ \\
\hline Occupation & $\begin{array}{l}\text { Unemployed } \\
\text { Unskilled worker } \\
\text { Semi-skilled worker } \\
\text { Skilled worker } \\
\text { Clerk/shop-owner/ } \\
\text { farmer } \\
\text { Semi-professional } \\
\text { Professional }\end{array}$ & $\begin{array}{l}2(0-10) \\
4(0-9) \\
4(0-10) \\
4(1.5-10.5) \\
2(0-4) \\
0(0-6) \\
2\end{array}$ & $.739^{c}$ & $\begin{array}{l}0(0-2) \\
2(0-4) \\
2(0-8) \\
0(0-2) \\
0(0-1.5) \\
0 \\
0\end{array}$ & $.152^{c}$ & $\begin{array}{l}2(2-12) \\
2(0-8) \\
4(0-12) \\
4(0-7) \\
4(0-6) \\
\\
0(0-6) \\
8\end{array}$ & $.753^{c}$ \\
\hline Socio-economic class & $\begin{array}{l}\text { Upper class } \\
\text { Upper middle class } \\
\text { Middle class } \\
\text { Lower middle class } \\
\text { Lower class }\end{array}$ & $\begin{array}{l}0(0-3) \\
2(0-10) \\
2(0-12) \\
4(1-8) \\
2(0-6)\end{array}$ & $.383^{c}$ & $\begin{array}{l}0 \\
0(0-4) \\
2(0-8) \\
2(0-2) \\
0(0-2)\end{array}$ & $.253^{\mathrm{c}}$ & $\begin{array}{l}0(0-6) \\
4(0-10) \\
4(0-12) \\
2(1-9) \\
4(0-8)\end{array}$ & $.495^{c}$ \\
\hline $\begin{array}{l}\text { Type of genetic disease being } \\
\text { cared for }\end{array}$ & $\begin{array}{l}\text { Structural genetic } \\
\text { disease } \\
\text { Functional genetic } \\
\text { disease }\end{array}$ & $\begin{array}{l}2(2-7.5) \\
2(0-7)\end{array}$ & $.829^{b}$ & $\begin{array}{l}0(0-3.5) \\
0(0-2)\end{array}$ & $.918^{\mathrm{b}}$ & $\begin{array}{l}2(0-10) \\
4(0-8)\end{array}$ & $.561^{\mathrm{b}}$ \\
\hline
\end{tabular}

${ }^{a}$ p-value $<0.05$ is statistically significant.

b - Mann Whitney $U$ test.

c - Kruskal Wallis test.

Table 4

Correlation between Quality of life and depression, anxiety and stress among the caregivers; $\mathrm{N}=101$.

\begin{tabular}{lllll}
\hline & & Depression & Anxiety & Stress \\
\hline Domain 1 (Physical) & $\mathrm{r}$ & -.261 & -.185 & -.167 \\
& $\mathrm{p}$ &. $\mathbf{0 0 9}$ & .065 & .098 \\
\cline { 2 - 5 } Domain 2 (Psychological) & $\mathrm{r}$ & -.436 & -.315 & -.327 \\
& $\mathrm{p}$ & $\mathbf{. 0 0 0}^{\mathrm{a}}$ & $\mathbf{. 0 0 1}$ & $\mathbf{. 0 0 1}^{\mathrm{a}}$ \\
\cline { 2 - 5 } Domain 3 (Social) & $\mathrm{r}$ & -.263 & -.161 & -.229 \\
& $\mathrm{p}$ &. $\mathbf{0 0 8}$ & .11 & $\mathbf{. 0 2 2}^{\mathrm{a}}$ \\
\hline Domain4 (Environmental) & $\mathrm{r}$ & -.257 & -.208 & -.211 \\
& $\mathrm{p}$ & $\mathbf{. 0 1 0}^{\mathrm{a}}$ &. $\mathbf{0 3 8 ^ { \mathrm { a } }}$ &. $\mathbf{0 3 5}^{\mathrm{a}}$ \\
\hline
\end{tabular}

r- Pearson correlation coefficient.

${ }^{\text {a }}$ p-value $<0.05$ is statistically significant. to meet these needs. All these can contribute to the psychological domain being affected the most in our study. ${ }^{5}$ The psychological interventions targeted on the identification of affected domain, together with the positive reappraisal of the stressful situation, can pave way to appropriate coping strategies and improve the parents' quality of life. ${ }^{9}$

On comparing the median scores of these domains across various factors we found that there was a significant difference in median scores in quality of life in Domain 3 (Social relationships) with respect to the type of genetic diseases being cared for. Caregivers have to spend much time in caring for the children and attending to their therapy. Often they are worried about explaining the situation to their friends and family, especially when the children exhibit unpredictable social behaviors. In order to avoid such situation's they tend not to be a part of social activities, hence affecting their social life. ${ }^{7}$ In the present study environment domain was affected the most following psychological domain. Etemad et al. in a study among parents of phenylketonuria and Vanz et al. among caregivers of osteogenesis imperfecta patients also reported that environment domains were mostly affected. ${ }^{10,11}$ In our study there was a significant difference in median scores in the quality of life in 
Domain 4 (Environment) with respect to religion and socio-economic class. The median scores were lowest among Hindus and among the middle class. In a study conducted by Leung et al. among parents of children with disabilities, it was shown that mean scores were low across all domains, with a significant difference in scores of social and environmental domains compared to parents of normal children. All these studies show that besides the psychological and social domains, environment domain is largely affected. This can be attributed to the cost of life long treatment and therapy, feeling of insecurity, uncertainty about the cause, prognosis and course of diseases and associated apprehension and difficulty in accessing genetic counselling and testing services. ${ }^{5,7}$

In the present study among 101 caregivers $18 \%$ had mild to moderate depression and $5 \%$ had severe depression. Anxiety and stress was present among $11 \%$. In our study more caregivers were found to have depression. Biber et at states that among parents of children with congenital heart defects the prevalence of depression was $18 \%$ and anxiety was $16-18 \% .{ }^{12}$ There was a significant difference in median scores of depression, anxiety and stress across gender and anxiety across age groups in the present study. Females showed higher scores for depression, anxiety and stress compared to males. A comparative study between normal and children with mental retardation (MR) found impairment in all the four assessed domains of QoL in the latter group. This was even more among mothers, as in our study. ${ }^{13}$ Mothers are vulnerable to stress and its impact, due to time spent in care, obligation for leaving their job and neglect of their health. However supportive marital partnership, social and moral support would assist in better coping with the situation. ${ }^{14}$

The anxiety scores were higher in the younger age group (18-27 years). Jameel et al. in his study comparing parents of Down syndrome children and normal children showed that level of depression, anxiety and stress are significantly higher in parents of Down syndrome children attributed to physical and intellectual disability of the child and associated chronic complications. ${ }^{15}$ Parents of children with genetic diseases are vulnerable, especially if they are young, however mindfulness and positive adaptation tends to develop sooner, with improved psychosocial support and better awareness about the disease. ${ }^{16}$

The unfulfilled demands encountered by these parents are universally linked to stress in general, there could be certain specific factors that directly impact parents and their QoL. The study by Darla et al. found that worry and communication had lowest mean scores followed by social functioning and daily activities; perhaps due insufficient social and government support besides stigma attached to disability. ${ }^{17}$ In the study by lane et al. among CHD patients found, inoperable or cyanotic conditions and, surgically cured, had the poorest quality of life due to significantly poorer levels of physical functioning and overall general health. Hence the QoL undeniably depends upon the type of genetic disease, its presentation, and associated comorbidities. ${ }^{18}$

Major issue pertaining to genetic disorders especially in developing countries is the access and quality of health care, post diagnosis. The perceived stress encountered by the caregivers of affected child has been emphasized, but the contributing factors are not always carefully analyzed. ${ }^{19}$ Hence the health care system must be strengthened to provide holistic care to every strata of the society with adequate inclusion of children with genetic disorders.

\section{Conclusion}

Quality of life and mental health status of caregivers can be affected to various degree and are influenced by many factors. The quality of life in psychological health, environment and social relationships were affected the most in the present study. Social relationship had an association with the type of genetic disease being care for. Depression, anxiety and stress were also common, especially among female caregivers. These factors are aggravated by low accessibility, cost and quality of health care. Awareness about the disease, service accessibility along with psychosocial support can help in positive adaptation.

\subsection{Limitations}

The quality of life and depression, anxiety and stress were assessed on one occasion. To assess the long term impact of genetic diseases it would require multiple follow ups with qualitative enquiry. This was a hospital based study with limited sample, it would require a community based study with larger sample to assess the burden.

\subsection{Recommendations}

Genetic counselling services should be made available at tertiary care centers for pre-marital counselling and carrier screening. It is the need of the hour to widen diagnostic, treatment and rehabilitative facilities.

\section{Funding}

Nil.

\section{CRediT authorship contribution statement}

Aparna Mohandas: Conceptualization, Methodology, Formal analysis, Investigation, Data curation, Writing - original draft, Writing review \& editing. Deepa Bhat: Conceptualization, Methodology, Investigation, Supervision, Writing - original draft, Writing - review \& editing. Sunil Kumar D: Conceptualization, Methodology, Formal analysis, Writing - original draft, Writing - review \& editing, Supervision. M.R. Narayana Murthy: Conceptualization, Methodology, Writing - review \& editing, Supervision.

\section{Declaration of competing interest}

Nil.

\section{References}

1 Congenital anomalies [Internet]. World Health Organization. [cited 2020 Sep 30]. Available from: https://www.who.int/news-room/fact-sheets/detail/congenitalanomalies.

2 Christianson A, Howson CP, Modell B. March of Dimes: Global Report on Birth Defects, the Hidden Toll of Dying and Disabled Children. New York: March of Dimes Birth Defects Foundation; 2006.

3 Rao VB, Ghosh K. Chromosomal variants and genetic diseases. Indian J Hum Genet. 2005;11:59-60.

4 Whoqol - measuring quality of Life| the World health organization [Internet]. [cited 2020 Nov 15]. Available from: https://www.who.int/toolkits/whoqol.

5 Buzatto LL, Beresin R. Quality of life of parents with Down syndrome children. einstein. 2008;6(2):175-181.

6 Landfeldt E, Lindgren P, Bell CF, et al. Quantifying the burden of caregiving in Duchenne muscular dystrophy. J Neurol. 2016 May;263(5):906-915.

7 Yuen Shan Leung C, Wai Ping Li-Tsang C. Quality of life of parents who have children with disabilities. Hong Kong J Occup Ther. 2003;13(1):19-24.

8 Structural and functional birth defects [Internet]. Birth Defect Research for Children. [cited 2020 Oct 27]. Available from: https://birthdefects.org/structural-and-functi onal-birth-defects/.

9 Roncada C, Dias CP, Goecks S, Cidade SE, Pitrez PM. Usefulness of the WHOQOLBREF questionnaire in assessing the quality of life of parents of children with asthma. Revista Paulista de Pediatria. 2015 Sep;33(3):267-273.

10 Etemad K, Heidari A, Setoodeh A, et al. Health-related quality of life of parents of children with phenylketonuria in Tehran Province, Islamic Republic of Iran. East Mediterr Health J. 2020 Mar 1;26(3):331-339.

11 Vanz AP, Félix TM, da Rocha NS, Schwartz IVD. Quality of life in caregivers of children and adolescents with Osteogenesis Imperfecta. Health Qual Life Outcome. 2015 Dec;13(1):41.

12 Biber S, Andonian C, Beckmann J, et al. Current research status on the psychological situation of parents of children with congenital heart disease. Cardiovasc Diagn Ther. 2019 Oct; 9(S2):S369-S376.

13 Malhotra S, Khan W, Bhatia MS. Quality of life of parents having children with developmental disabilities. Delhi psychiatry journal. 2012 Apr;15(1):171-176.

14 Durmaz A, Cankaya T, Durmaz B, et al. Interview with parents of children with Down syndrome: their perceptions and feelings. Indian J Pediatr. 2011 Jun;78(6):698-702.

15 Jameel HT, Rafiq S, Kalsoom U. A study on level of depression, anxiety and stress among parents of Down syndrome children versus parents of healthy children. Int $J$ Biol Pharm Allied Sci. 2016;5(7):1553-1560. 
16 Dellve L, Samuelsson L, Tallborn A, Fasth A, Hallberg LR-M. Stress and well-being among parents of children with rare diseases: a prospective intervention study. J Adv Nurs. 2006 Feb;53(4):392-402.

17 Darla S, Bhat D. Health-related quality of life and coping strategies among families with Down syndrome children in South India. Online on Med J Armed Forces India. 2020 Oct 9. https://doi.org/10.1016/j.mjafi.2020.07.010.
18 Lane DA, Lip GY, Millane TA. Quality of life in adults with congenital heart disease. Heart. 2002 Jul 1;88(1):71-75.

19 Oliveira ED, Limongi SC. Quality of life of parents/caregivers of children and adolescents with Down syndrome. Jornal da Sociedade Brasileira de Fonoaudiologia. 2011 Dec;23(4):321-327. 